\title{
Redevelopment of the roof structure in the production plant of Skoda Auto a.s. in Kvasiny
}

\author{
Luboš Podolka ${ }^{1, *}$ \\ ${ }^{1}$ University of technology and economics in Czech Budejovice, Department of civil engineering, \\ 37001 Czech Budejovice, Czech Republic
}

\begin{abstract}
The paper describes a proposal for the redevelopment of the roof structure using FRP materials. During the design of the redevelopment, the experience of experiments with FRP materials that took place in the PAVUS a.s. laboratory in Veselí nad Lužnicí and laboratory of Faculty of Civil Engineering of the Czech Technical University in Prague was used. Initial experiments used for the later proposal of redeveloping supporting structures are also described and some are compared with the mathematical model of the ATENA software. The experiments in the PAVUS laboratory resulting in the adjustment of the anchoring length correspond to the required fire resistance. The result of the Faculty of Civil Engineering of the Czech Technical University in Prague laboratory experiment is the design of the optimal shape of the FRP shear reinforcements. In the article there are also photos from the implementation of the roof redevelopment.
\end{abstract}

\section{Introduction - Description of reinforces structure}

Part of the assembly hall was built in the second half of 2005 as an annex for the Roomster model production line.

The existing load bearing structure of the assembly hall annex consists of a prefabricated reinforced concrete skeleton hall with a width of naves $2 \times 18 \mathrm{~m}$ and a zone located by the northern facade with a built-in other floor with a span of supporting structures measuring $6.0 \mathrm{~m}$. In the longitudinal direction, the hall consists of three separate dilatation parts with a column module measuring $12.0 \mathrm{~m}$. The headroom under the trusses of the hall is about $9.5 \mathrm{~m}$.

A part of the building has two floors. The vertical structure of the assembled skeleton of the hall consists of columns with a square (or rectangular) cross-section with a side length of $600 \mathrm{~mm}$.

The roof structure has the shape of a gabled roof with a gradient of $2 \%$ and inner valleys. On a major portion of the roof there are transverse separated arc-shaped skylight strips made of Makrolon - the purlins of the gable shape support the transverse (in the direction of the skylights) beams along skylights, which then support a pair of prefabricated concrete skylight rims. The roof cladding is lightweight and insulated with a supporting

\footnotetext{
*Corresponding author: podolka@mail.vstecb.cz
} 
structure made of a trapezoidal sheet, on which is a roof waterproofing membrane, stressed due to wind suction load, anchored by self-tapping screws (through a soft thermal insulation layer).

Trusses (beams) have a longitudinal direction span of $12.0 \mathrm{~m}$. In terms of load transfer, they function as continuous beams of six, or four fields with embedded joints in approximately a quarter of the range field. Statically it is a continuous beam with internal joints (i.e. Gerber girder). Trusses form the gabled roof. Their span is 18.0 meters and the axial distance between the trusses is 6.0 meters. In the trusses there are circular holes in the web for the passage of wiring.

Trusses (beams) have a reinforced concrete T-shaped cross section with the web measuring a height of $1.05 \mathrm{~m}$ and a width of $220 \mathrm{~mm}$. The upper flange has a width of $400 \mathrm{~mm}$ and height of $200 \mathrm{~mm}$ - the haunch between the web and the flange is made with a height of $50 \mathrm{~mm}$. Purlins with a height of $1.45 \mathrm{~m}$ are designed as garble concrete elements with a T-shaped cross section with a slope of $2 \%$. In their web with a width of $160 \mathrm{~mm}$ there are circular holes for the passage of wiring. To the top flange with a width of $360 \mathrm{~mm}$ (in the field with a height of $150 \mathrm{~mm}$ and placement at a height of $300 \mathrm{~mm}$ ) there is anchored a trapezoidal sheet with a height of $150 \mathrm{~mm}$, which forms a supporting structure of the roofing.

\section{Condition of supporting roofing structure}

The existing concrete structure (especially prefabricated trusses in modular axis "F") is damaged mainly by shear cracking caused by static load effects (width of cracks caused by bending stress is significantly smaller). According to a more accurate measurement by optical micrometer and inaccurate measurement by triangular scale the width of cracks varies from 0.4 to $2.5 \mathrm{~mm}$ (in one case even 3.5 to $4.0 \mathrm{~mm}$ ).

\subsection{Based on the findings of the structural and technical survey of selected elements of the prefabricated roof parts it can be stated as follows}

- The profile and location of the built concrete reinforcement practically corresponds with the production documentation,

- The strength grade of the concrete in trusses (beams) was determined as class C 20/25 (B 25) and does not conform to the required 500 mark of concrete recorded in the drawings (mark of the required concrete strength corresponds with class C 35/45),

- Modulus of concrete elasticity in the compression of collected samples was determined as $23.8 \mathrm{GPa}$.

\subsection{Based on the results of comparative calculations for the selected elements of the prefabricated roof parts it can be stated as follows}

- The shear resistance of the reinforced concrete sections for trusses (beams) is due to inappropriately spaced stirrups, insufficient for practically their entire length,

- Areas of discontinuities of reinforced concrete cross-sections (webs weakened by circular holes and changes in the cross-sectional height of placement on lock joints) are not sufficient due to the lack of embedded tensile reinforcement. 


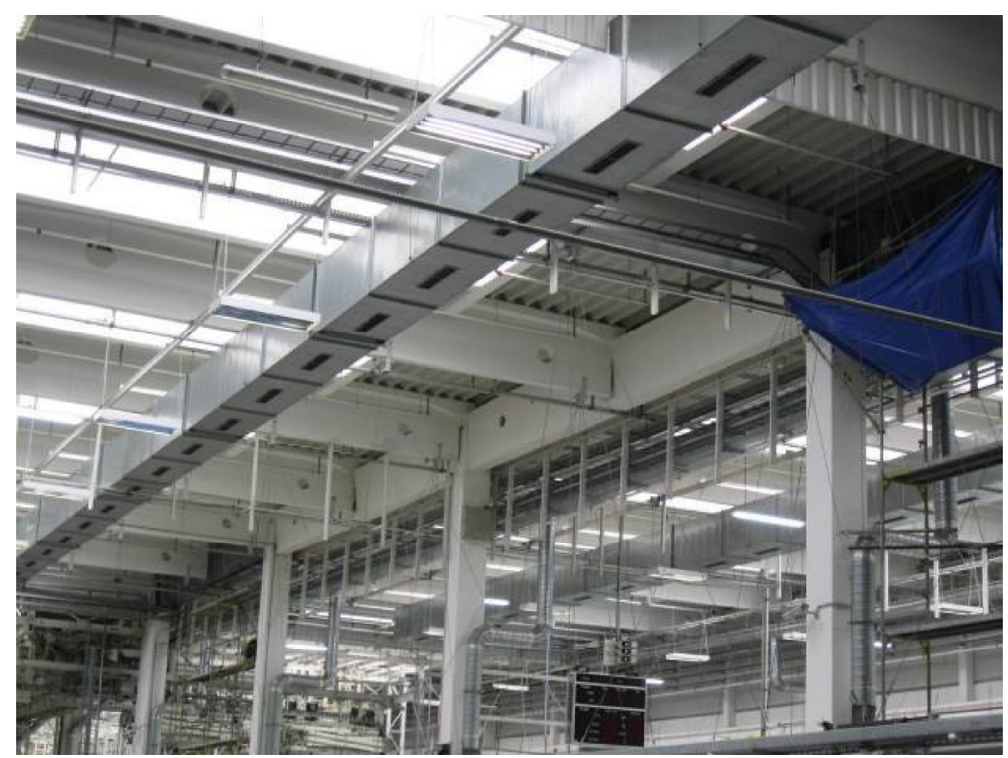

Fig. 1. Reinforced roof structure.
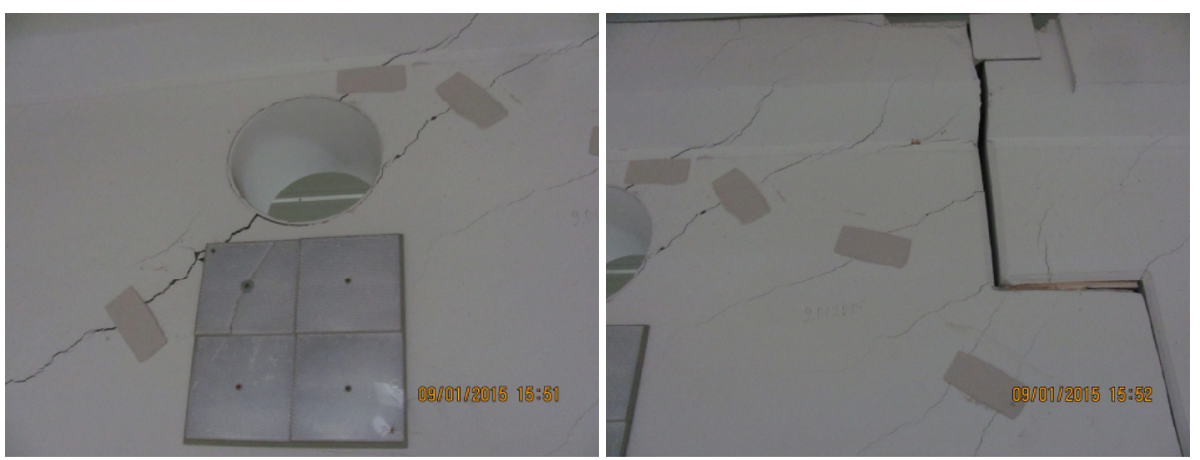

Fig. 2. Details of shear cracks in the beam.

\section{Draft remediation design}

The redevelopment of the structure is designed using FRP materials in the form of shear and bending reinforcement, FRP fabrics. The assessment of cross-sections and design of reinforcement is based on the principle of truss analogy that describes the behavior of the structure girder in the place of the mutual placing of elements on each other, where they form short bracket joints of a pair of beams [1-2].
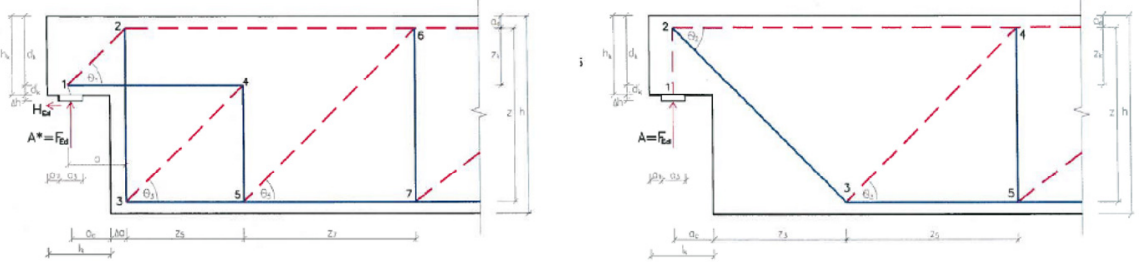

Fig. 3. Models of placing truss based on truss analogy. 
FRP material contribution to shear resistance, $\mathrm{V}_{\mathrm{fd}}$, "reinforcement by vertical fabric"

For example: Sheet $240, \mathrm{E}_{\mathrm{fu}}=240 \mathrm{GPa}$, thickness $\mathrm{t}_{\mathrm{f}}=1,176.10-4 \mathrm{~m}, \varepsilon_{\mathrm{fd}, \mathrm{e}}=0.002$ up to 0.004 , at angle $\alpha=90^{\circ}$, i.e. vertically.

$$
V_{R d}=\min \left(V_{c d}+V_{w d}+V_{f d}, V_{R d 2}\right)
$$

where the bearing capacity of the FRP reinforcement is calculated using following formula:

$$
V_{f d}=0.9 \cdot \varepsilon_{f d, e} \cdot E_{f u} \cdot \rho_{f} \cdot b_{w} \cdot d \cdot(\cot \theta+\cot \alpha) \cdot \sin \alpha
$$

$\varepsilon_{f d, e} \quad$... a design parameter of effective FRP deformation

$b_{w} \quad \ldots$ minimal cross-sectional width above the effective depth

$d \quad$...effective cross-sectional height

$\rho_{f} \quad \ldots F R P$, reinforced, straight $2 t_{f} \cdot \sin \alpha / b_{w}$ for the bevel cut, shear reinforcement

thickness $t_{f}$

( $b_{w}=$ the minimum width of the concrete cross section above effective height),

or $\left(2 t_{f} / b_{w}\right) .\left(b_{f} / s_{f}\right)$ for FRP reinforcement in the form of strips of fabric with width $b_{f}$ at the

span $\mathrm{s}_{\mathrm{f}}$

$E_{f u} \quad \ldots$ elasticity modulus of FRP in the direction of fiber orientation

$\theta \quad \ldots$ angle of diagonal shear cracks from the plane, mostly $45^{\circ}$

$\alpha \quad \ldots$ angle between the fibers and the plane

\section{Experimental verification of anchoring length slats}

To determine the anchor length of FRP materials there were created divided bars with the dimensions $150 \times 150 \times 600 \mathrm{~mm}$ with an embedded reinforcement $\varnothing 20 \mathrm{~mm}$ provided with an anchor plate sheet thickness $=8 \mathrm{~mm}$, dimensions $150 \times 150 \mathrm{~mm}$. The reinforcement was butt-welded to the plate. On the outer face of the bars there were glued slats with different anchor length; $50 \mathrm{~mm}, 100 \mathrm{~mm}$ and $150 \mathrm{~mm}$ from various concretes: C 16/20, C 30/37 and C 50/60. To verify the effect of the temperature on the anchorage length, tests were conducted in the PAVUS laboratory on bars measuring $150 \times 150 \times 800 \mathrm{~mm}$, with $500 \mathrm{~mm}$ slat, which was unprotected or protected against higher temperatures using cladding from the Grena a.s. company, boards made from Vermiculite.
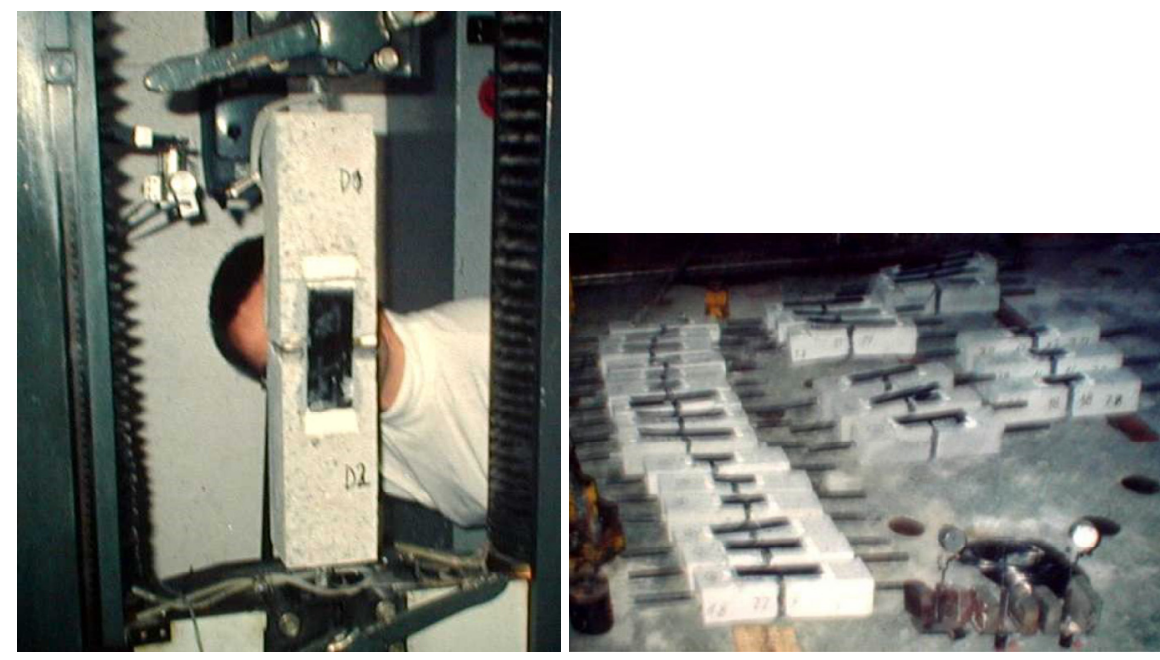

Fig. 4. Experimental tests to verify the length of anchor slats 

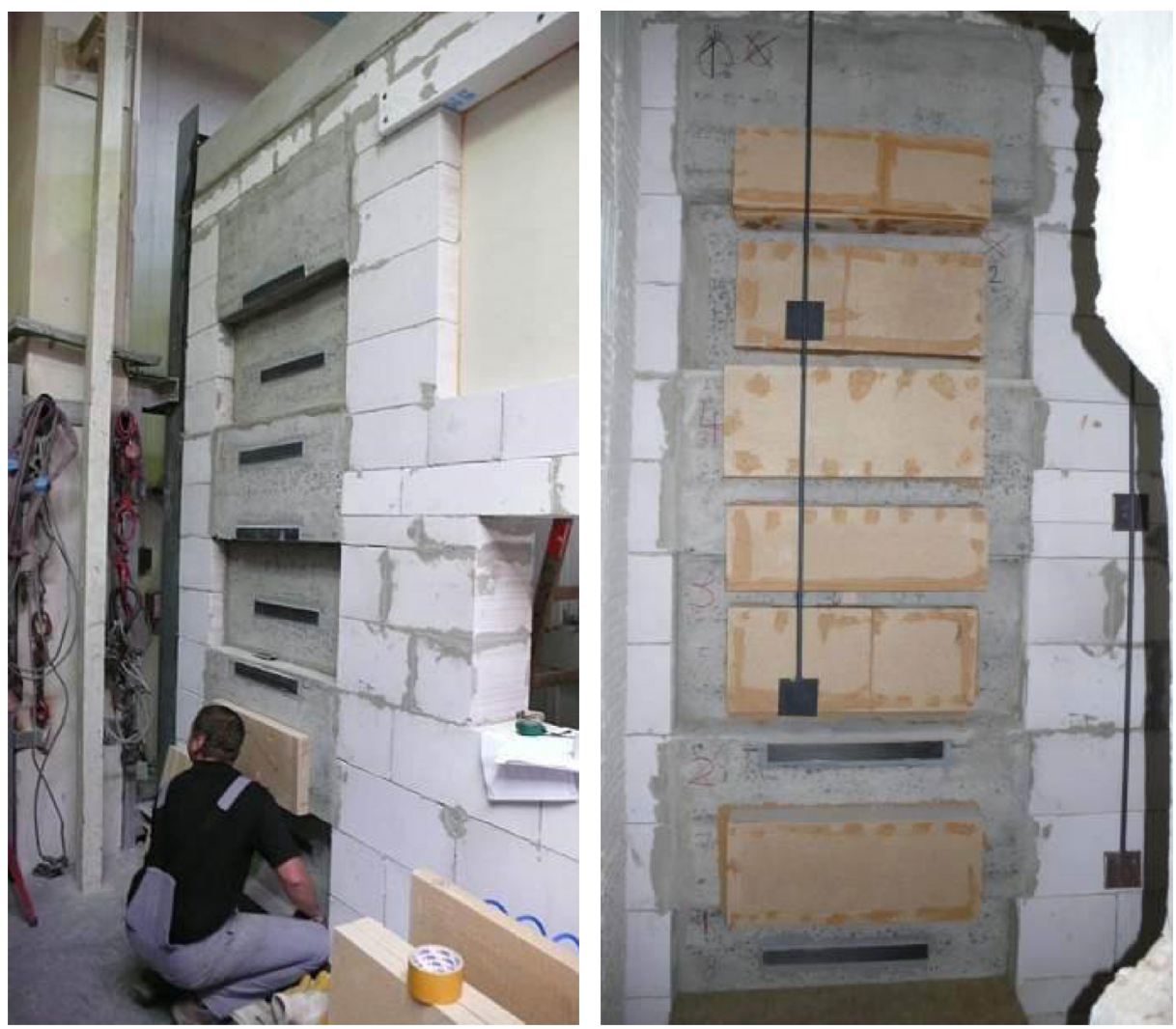

Fig. 5. Preparation of an experimental test in a fire test furnace. Left fixing cladding on glued slats, on the right finished cladding with two slats left without protection.
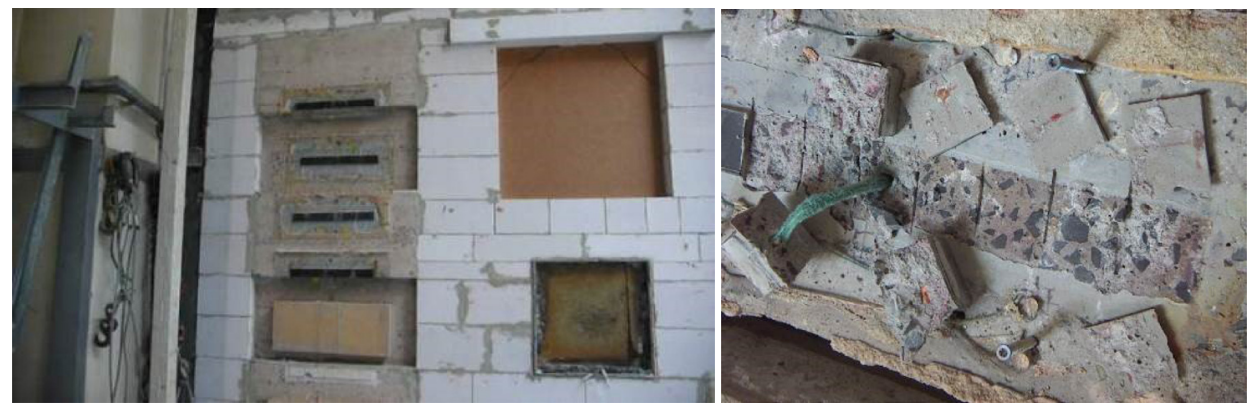

Fig. 6. Slats after fireproof cladding was removed (left), on the right a detail of sawn slats and exposed concrete.

The experiment determined the requirement of extending the length of the anchoring slats by $50 \mathrm{~mm}$ in order to ensure sufficient fire resistance in comparison with an anchor length without requirement for fire resistance.

The alternative to facing boards of Vermiculite for FRP plates for FRP lining fabric using a fiberglass covered with cement plaster. 


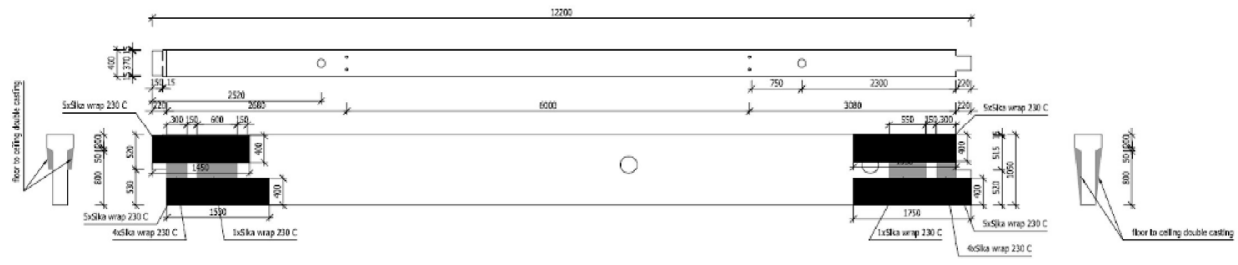

Fig. 7. Shape of the truss, its reinforcement and the proposed reinforcement of the truss using FRP fabrics.
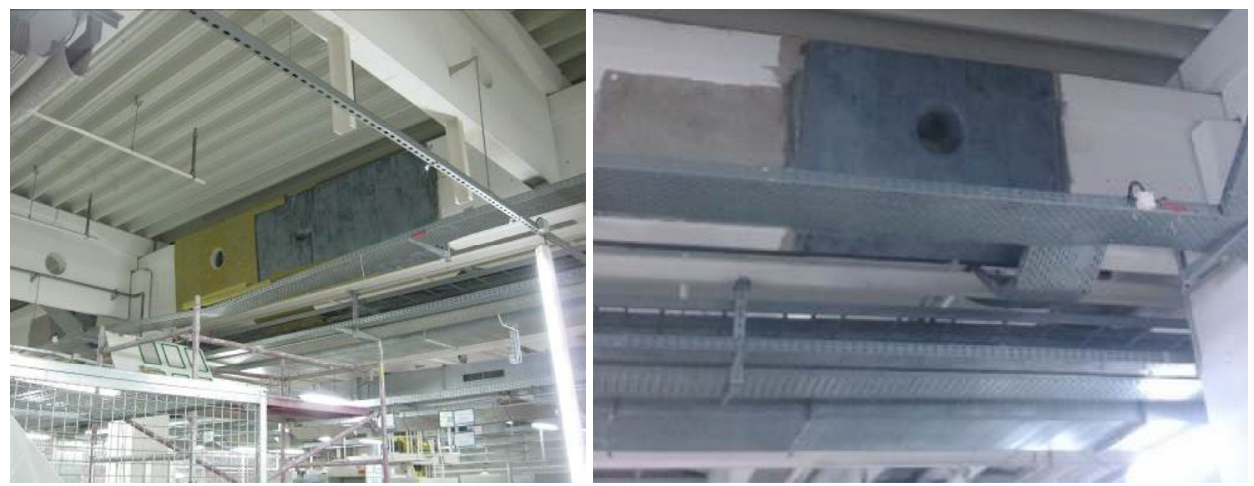

Fig. 8. Reinforcement using FRP fabric.
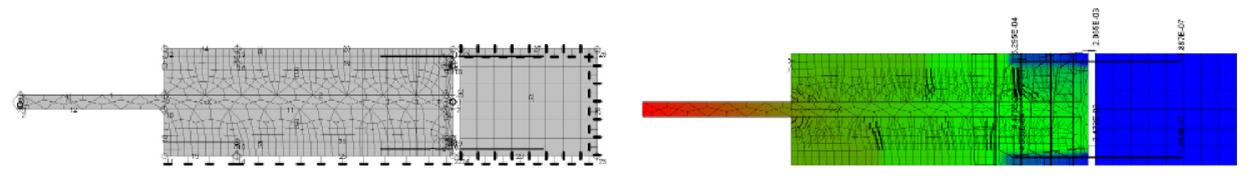

Fig. 9. The mathematical model to verify the anchor length created in the Atena software and The stress in the cross section shown in the mathematical model.

The above described experimental element was modeled in program ATENA, so that it can monitor the behavior of the element in place both active and passive anchors, i.e. power transfer from reinforcing bars through mechanical anchoring to the concrete and spread stresses in the concrete for anchors.

\section{Conclusion}

The commenced assembly of a new car model at the Skoda Auto a.s. factory in Kvasiny proved the functionality of the proposed solution. Since the application of the reinforcement there has not been any damage to the roof structure caused by the applied load.

\section{References}

1. EN 1992-1-1 Eurocode 2: Design of concrete structures. Part 1-1: General rules and rules for buildings (1992)

2. Externally bonded FRP reinforcement for $R C$ structures Technical report on the "Design and use of externally bonded fiber reinforced polymer reinforcement (FRP EBR) for reinforced concrete structures" by 'EBR' working party of fib TG 9.3 (2001) 